This is the author's accepted manuscript of the following article: Staples, J. (2012), "Culture and carelessness: Constituting disability in South India", Medical Anthropoloy Quarterly, 26(4), 557-574, which has been published in final form at http://dx.doi.org/10.1111/maq.12007.

\title{
Culture and carelessness: constituting disability in South India
}

\section{James Staples, Brunel University}

\begin{abstract}
Professional and lay explanations of disability, collected via interviews and participant observation during fieldwork in Hyderabad, South India, identify 'carelessness' and 'superstition' as major impediments to good health among the general population, and education as the key solution. In that such findings suggest a valorisation of personal responsibility for self-care, the Foucauldian concept of biopower appeared a salient framework for analysis. While illuminating, however, biopower was ultimately inadequate for explaining what emerged, on closer analysis, as significant discrepancies between assumptions about how disabled people engaged with healthcare services and their actual beliefs and practices; and between the moral interpretations different stakeholders made of 'carelessness' in describing perceived causes of disability. My data also suggested that education was not in itself a key determinant in people's healthcare decisions. This article explores these differences between official and demotic discourses concerning the causes of disability and attempts to account for them ethnographically.
\end{abstract}

\section{Key words}

Disability, impairment, culture, biopolitics, India, Hyderabad

\section{INTRODUCTION}

Officially sanctioned categorisations of 'disability' in India, I argue in this article, are at least partially constituted by dominant 'discourses of truth' (Foucault 1994:31), biomedicine among them, with disability framed as a public health issue to be addressed through 
medically-informed interventions. These interventions are in turn validated and enabled through public health education and campaigns - sponsored by NGOs, the state and international medical organisations - that locate responsibility for negatively construed bodily differences in the affected individual and his or her family. This framing informs and naturalises decisions taken about, for example, treatment and rehabilitation of those socially constituted as 'the disabled'. It also defines, within tight constraints, the very terms within which ‘disability' - long since exposed by Disability Studies (DS) scholars as a fluid social category rather than an objective medical one (Barnes and Mercer 2003; Shakespeare 2006; Shuttleworth and Kasnitz 2004; Thomas \& Corker 2002; Tremain 2002; Staples 2011) - may be imagined and acted upon. This has implications for how families make decisions concerning the relative social worth of those of its members whose bodies are configured or perform differently to the mainstream.

In addition to analysing how, why and the extent to which disabled people in South India are constituted as personally responsible for their bodily conditions, I also identify alternatives to this position, in doing so questioning whether official medical discourses are as dominant as they at first appear in structuring how people constituted, understood, and subsequently responded to disability and disabled people. While, on the one hand, biopolitics over-determines official rhetoric and policy concerning disability, in so doing shaping and constraining its public discussion, on the other hand, this rhetoric masks alternative discourses that might better reflect quotidian experiences of disability. In this article I attempt to draw out these different levels of interpretation and to chart their interplay. I also consider the practical implications of a rhetoric rooted in the biopower model for public health responses to disability.

\section{Fieldsites and Methodology}


My fieldwork in Hyderabad, South India (September 2005-December 2006), explored how disability - described locally as vikalangumu (Telugu) and vikalang (Hindu) - was constituted as a social category encompassing various negatively construed bodily differences. I conducted research, with a local research assistant, in multiple locations: in hospitals; in disabled people's homes; in public places; in disability activists' offices; in a small settlement of disabled people on the peripheries of the city; and at public meetings and NGO workshops. Informants were drawn from across socio-economic divides: from uppermiddle class families who could afford to attend a neurosurgeon's private clinic to those begging for their living on the streets. They were also broadly representative in terms of age, gender, and the communal make-up of the city (predominantly Hindu but with a large Muslim minority).

My initial intention was to limit my focus to bodily differences caused by particular conditions. To this end I undertook interviews with 100 families whose children had been diagnosed with cerebral palsy and with 82 sight-impaired people, recruited at out-patient clinics or during field visits with social workers and paramedics. On the ground, however, such distinctions were significantly blurred: many organisations I spent time with worked across impairment categories; my own categories were not mutually exclusive; and people defined by those around them as disabled often identified themselves more generally than my limiting categorisations allowed. The majority of self-identified disabled people I met described their impairments in relation to what their bodies could or could not do rather than in terms of a named condition. There was also the broader epistemological problem that in identifying particular conditions as disabilities or impairments I was reifying abstract, contextually-defined categories. Accepting that both disability and impairment, as identified by DS scholars, are as socially and environmentally constructed as they are descriptors of 
individual conditions, I consequently came to focus on the more general problematic of how and when notions of 'disability' were invoked, and tried to analyse why.

This article draws on observations and conversations in the contexts described above, and on in-depth, open-ended interviews with people I met in them. In addition to those who defined themselves, or were defined by others, as disabled, I also interviewed and spent time with doctors and other healthcare professionals; disability activists; parents, siblings and carers of disabled people; and charity workers involved in rehabilitation. The institutional perspectives of health professionals identified as a consequence of those encounters are a particular focus of this article. Specifically, I worked with doctors, rehabilitation specialists and physiotherapists in three regular out-patient clinics - one dealing with cerebral palsy and related cases; one in managing the practical effects of sight-impairments; and the third a private paediatric clinic for children with various physical impairments. In each of these contexts, as well as observing the clinics as they took place and arranging to interview patients separately, I also spoke to the health professionals between patients, and, later, conducted more formal interviews with several of them. I also accompanied paramedics from the first two hospitals when they went to visit patients at home, and observed and spoke with similar professionals in several rehabilitation centres as they went about their daily work.

Since 'disability' is constituted at least as much by 'outsiders' as from within, however, I also worked with the lay public. In Hyderabad, this meant noting what those I met - local shopkeepers and street traders, auto rickshaw drivers, students, teachers, municipal officials, and fellow customers at tea stands and snack kiosks - had to say about the issues I was exploring. In the provincial town adjacent to where I conducted earlier fieldwork in coastal Andhra Pradesh (see Staples 2007a) - which I visited several times during my Hyderabad fieldwork - I discussed the same topics with a similar range of people, including 
farmers and field labourers. In doing so I amassed a total of 60 semi-structured interviews, and notes on many more casual conversations.

Public perspectives on disability, this data suggests, mirror the same Foucauldian biopolitics that shaped dominant professional and official discourses. From both perspectives, responsibility for causing disability appeared to be located in individuals and their families. However, prolonged encounters with lay and disabled people in Hyderabad served significantly to nuance my interview data, suggesting not just differences between medical and lay opinion - hardly unexpected - but between opinions and practices widely attributed to the lay public through official discourses, and those which emerged through my ethnographic analysis.

\section{Situating the research problem}

According to Rabinow and Rose (1994), drawing on Foucault (1978), biopower is the capacity of the state to control what were once considered the subjective, private concerns of citizens: activities such as the care and management of one's body and, consequently, life itself. This is achieved not through coercion but through the propagation of dominant truth discourses - about, for example, health - which foreclose alternative ideologies and constrain populations to think and behave within particular parameters (Rose 1990:ix; Rabinow and Rose 1994; Rose 2007). Biopower, as Rose identifies, has been scaled-down from a 'biopolitics of populations' (Foucault 1978:139) to self-management by 'newly responsibilized individuals and smaller groups' (Hannah 2011:1040). If successfully executed, then, particular bodily conditions or deviations from the average can be negatively re-categorised as pathological and, by reference to an imperative for self-care, those affected or those close to them can be held responsible for their own conditions. This culpability is further compounded if what are considered to be the appropriate steps to seek cure or correction are not taken. 
'Every citizen,' as Rose expresses it, 'must now become an active partner in the drive for health, accepting their responsibility for securing their own well-being' (2007:63). Being ill or disabled within such a dominant worldview is not just the 'personal tragedy' that medical models of disability have been accused of reducing it to (Oliver 1990); rather, choices taken by the ill and the disabled and their families are seen as causing their bodily conditions.

When such positions become naturalised through the kind of dominant truth discourses Foucault describes, institutional responses to negatively construed bodily conditions might logically be framed in terms of education and in changing the ways of marginalized groups rather than making the wider structural changes - such as redistribution of wealth - that alternative explanations of disability might promote. So, while some might draw attention to the life affirming qualities of biopolitics as forms of power aimed at valuing and supporting life (Hannah 2010), it also, in its microforms, shifts responsibility from the state and culpable institutions on to the individual targets of medical interventions and rehabilitation. As I shall discuss, it might also account for why public health education programmes have such a low rate of success

In that a high proportion of the conversations I had with medical professionals about disability in Hyderabad referenced a discourse that cited careless or reckless behaviours, a lack of education and an enchantment with tradition as the predominant causes of disability, academic discussions of biopower and biopolitics clearly offered a useful initial frame for understanding the wider contexts that informed such discourses, hence aiding our understanding of lay notions of culpability, and of state and institutional measures to manage disability. That those same medical professionals related ignorance and carelessness to 'cultural beliefs' (Link \& Phelan et al 1999:1328) also references a much wider discussion within public health that goes beyond India. Writing in the mid-1950s about mental health, for example, Shirley Star argued that in order for patients to be treated successfully, a 
'veritable revolution in people's ideas about some very fundamental questions' was required (1955, cited Link \& Phelan et al 1999:1331). Lay beliefs about mental illness, like the lay beliefs several of the healthcare professionals I worked with alluded to, were seen as a fundamental barrier to good health. While Link and Phelan et al's (1999) later research suggests a narrowing of the gulf between lay and professional conceptions, others have identified a continuing and widespread connection drawn by health professionals and researchers between 'culture' - as a euphemism for negatively-construed difference - and the spread of disease (Saethre and Stadler 2009) or 'bad behaviour' more generally (Volpp 2000). Leach and Fairhead (2007), for example, document how ignorance, a lack of education and the persistence of 'traditional' ideas are also assumed to be barriers to medical interventions in West Africa, while Geffen (2005, cited in Niehaus 2009) likewise frames treatment programmes as a battle of 'science' over 'ignorance'. Given discrepancies between what are attributed to people as their 'cultural beliefs' and the beliefs to which they lay claim suggested both by the authors cited above and through my own fieldwork - the link drawn between culture and disability, with education cited as its antidote, requires further attention.

At the same time, however, while Foucauldian analyses imply increasing levels of self-surveillance and acceptance of personal or familial responsibility for ensuring one's health as moral imperatives, the extent to which my informants outside professional contexts - and especially those towards the bottom of the social hierarchy - fully situated themselves within this worldview is questionable. As Marsland and Prince argue in the introduction to this collection, self-care techniques are often unavailable to those anthropologists work with. Rather, as several commentators note (Braun 2007; Cheah 2007; Hannah 2011), while such forms of biopolitics might be salient in 'zones of liberal peace' (Braun 2007:25) in the relatively affluent West, the relocation of responsibility for management of the body to the self is less all-encompassing and less stable in the global South and, more generally, among 
women and lower socio-economic groups. While biopolitics clearly informs the rhetoric available for public framing of disability in India, then, my data suggest that it does not penetrate sufficiently deeply to serve as a single source of interpretation. Indeed, as I will show, people's lived experiences and behaviours often served as a direct challenge to the rhetoric of their first level comments and observations.

In the next section, I begin with a synthesis of the arguments most commonly made among the health professionals I worked with in accounting for disability.

\section{Three assumptions about disability and disabled people in South India}

Health professionals are not an undifferentiated mass, and my distillation of the dominant perspectives I summarise here draws on research in specifically clinical settings, rather than the more informal contexts in which I met my lay informants. Nevertheless, there were recurrent narratives that ran through my contacts with the professional group. The first of these is that many disabled people, and especially those from rural, uneducated and economically poor backgrounds, do not obtain suitable treatment for their bodily conditions. This is because a) they do not understand the nature of those conditions or realize they might be relieved or cured by biomedical intervention; and b) they are enthralled to superstition and traditional, unscientific methods of cure with few if any curative benefits. The paediatrician I worked with, for example, regularly commented of patients that their parents had wasted time in treating them with ineffective 'tree medicine' (local, plant-based cures) and the remedies of 'quacks and charlatans'. The neurosurgeon whose clinic I attended likewise blamed uneducated people's unwillingness to come to the hospital until hopes pinned upon sacrifices and prayers to particular gods and goddesses, or pilgrimages to sacred sites where they could appeal for a cure for their conditions, had been exhausted. 
A second, related, assumption is that many conditions are caused or made worse not only by a failure to access biomedical resources, but because of what was glossed, usually in English, as 'carelessness'. In more than half of my interviews with the lay public, as I shall expand upon later, respondents also answered questions about causes of disability with references to 'carelessness', the English word, or its Telugu equivalent, niralakshanam: phrases glossing a variety of meanings, but which suggest that people should have known better and could, by implication, have avoided their conditions. The medical professionals I worked with used the same notion to cover both preventable accidents - such as crashing a car or injuring oneself — and, more abstractly, to a lack of attention to moral codes. On the one hand, doctors I interviewed uniformly dismissed direct correlations between immoral behaviour and negatively-construed bodily differences as a feature of the superstition or 'culture' which they said stalled public health progress. They all said that people were wrong, for example, to attribute impairments to karma - deeds in former lives to which their current situation was a response. The neurosurgeon would comment to me regularly between patients on how rural/village/uneducated people (categories he used almost inter-changeably) would 'make sacrifices to this or that goddess' to atone for whatever behaviour had led to their current misfortune, and needed to be re-trained in more scientific explanations that would, in turn, cause them to seek biomedical care much earlier than they did at present. 'It is very difficult to explain to people the facts of their conditions,' concurred the paediatrician, speaking to me directly after a consultation with migrant labourers, who were concerned that their daughter could still not walk at the age of three years. 'They are ignorant, uneducated, will think about it being their fate rather than caused by a medical condition, so they might not even come forward for treatment, or will only come late.' On the other hand, several doctors I interviewed also drew implicit correlations between the fecklessness of some of their patients and their impairments: a moral depravity embodied in poor dietary choices; bad 
habits such as smoking, extra-marital sex and alcohol consumption; marriage to close relatives; and poor personal care. In the case of the migrant workers' daughter, for example, the doctor felt that the family's itinerant lifestyle - which included, he assumed, leaving the girl to play unattended at the roadside while her parents worked - had caused them not even to notice obvious health problems and to do nothing for a long time when they did. 'You see, they develop bad ways of doing things,' as the neurosurgeon put it in respect of his own patients from comparable backgrounds. 'They don't know it's wrong to do some of the things that we understand as improper - they've been brought up like that, it's what they see around them in the slums and the villages.'

The benign take on this assumption, and the one taken by all the medical professionals I encountered who expressed an opinion, was that people were unaware of how to care for themselves or their children, and so needed education and other forms of state intervention. A harsher reading, expressed by a few doctors and rehabilitation professionals in respect of particular patients, was that people were simply reckless with their health, taking unnecessary risks and then not visiting the doctor even when affordable care was available.

A third assumption follows from the first two: that is, that increased biomedical knowledge, imparted through health education programmes, will decrease the incidence of disability because people will learn to take preventative measures, and decrease suffering caused by disability because people will be able to seek appropriate treatments. The neurosurgeon, in particular, was keen to enlist me in his campaign for the government to spend more on public health education campaigns - pushing me to discover the 'cultural beliefs' that prevented people from responding appropriately to their conditions so that education could be addressed to specific problems - but all of my professional informants saw education as at least part of the solution to disabling conditions. 
All three of these broad assumptions, I argue, mask more complex lived realities. More significantly, they also locate causality of disease or disability firmly within the individual, family or social group concerned, rather than, for example, within wider economic and political conditions or state policies, which is where 'social models' of disability (see, e.g., Oliver 1990) would locate it.

\section{Lay perceptions about disability}

Given that public attitudes are shaped in important ways by the same discourses within which my professional informants positioned themselves, it is unsurprising that lay views on disability frequently bought into the same kind of assumptions. 'Carelessness' - both the English word and its Telugu equivalent - came up regularly, across social boundaries, in discussions about causality, and, although used loosely to gloss over what transpired to be a range of different perspectives or, sometimes, to avoid a more specific explanation, the term was generally used to locate cause in the disabled person or their carers. 'Carelessness' because, as several people expanded, 'they don't know any better' - was also seen as something that could be challenged by education. 'People neglect to go to the doctors and to the hospitals,' one farm labourer - a low caste [1] 35-year-old man - told me in an interview, 'even when free care is available, as it is in the Government hospitals.' A small group of urban middle class under-graduate arts students I was chatting to at a teashop expressed similar views, nodding in agreement at one of their group's suggestion, in English, that 'being backward in education and having a low level of awareness... are the key issues in people being handicapped.' Backwardness - a term in common, official usage in relation, for example, to 'backward castes' [2]- was used a great deal in discussions with my lay informants about disability, especially when I questioned them about causality. It was sometimes used in specific relation to people being 'economically backward': a euphemism 
for poverty, which also implicitly laid culpability for poverty on the poor, or inferred that the solution to their predicament lay in their own development rather than in wider external changes. 'Backwardness' was also used in a more general way. Mirroring the narratives I found among health professionals, one shopkeeper told me that those most likely to be disabled were 'the backward, the poor, the uneducated, and those who don't take proper care of their own lives.'

The most explicit example of laying culpability for impairments on disabled people themselves was from the caretaker of the building where I lived, a Hindu man from a midranking caste, in his late 60s. Those most likely to suffer disabilities, he told me in an interview, were those with 'bad habits', especially men who slept with 'bad women'. Another informant, too, identified 'the criminally minded' as the most likely to suffer impairments, not because of any kind of divine intervention (although karma was occasionally invoked as an explanation) but because not playing by the rules laid one more susceptible to accidents. Although other responses tended to be more temperate, many saw personal irresponsibility or recklessness as a central cause of impairments - a position which, at least on the surface, seems to mirror lay perspectives on negatively construed categories of ill-health in other parts of the world (e.g., Link and Phelan et al 1999). A high caste female lecturer from a college in the city, for instance, said those most likely to have disabled family members were 'people who don't take the birth of a child as a major responsibility and who don't visit doctors frequently during pregnancy. They are more likely to give birth to children with disabilities.'

As well as taking responsibility for themselves, it was also considered important by these informants that disabled people remained as independent as possible. 'I strictly never give to any disabled person begging,' said the college lecturer. 'I feel it is encouraging them even more to be dependant.' While most others claimed they were more likely to give money to disabled people begging than to others - because it was harder for the former to work - 
many, particularly those educated to degree-level and above, felt that employment was a better solution to meeting disabled people's needs. 'It's better to work, no?' said a teacher at a Hyderabad nursery school, 'because that way they can learn to help themselves. And if we have to give, it's better to give things like food, otherwise there's a danger they'll just spend it on drugs and alcohol.'

In expressing such opinions, my lay interviewees also expressed a particular fear of the 'other' against whom they attempted to contrast themselves, even when they, too, came from socially marginalized groups. Self-control, proper care of one's body, and independence, were, in line with a Foucauldian analysis of the kind outlined above, values to be propagated (see Ecks 2004). Indeed, the prospect that they or their children might also become disabled if they did not conduct themselves appropriately helped to ensure a form of self-surveillance, particularly among middle class informants.

This potent mingling of fear and disgust in response to bodily impairment was palpable in the reaction from one high caste and apparently wealthy woman we met in the waiting room of the eye hospital one morning. My research assistant and I had been talking to an older woman seated across the room from her, who had accompanied her 18 year old grandson to the hospital in the hope of getting him treatment for sight impairments that prevented him from bringing any income into the household. They were clearly very poor. Neither the grandmother nor her grandson wore shoes and both were shabbily dressed. They had travelled the hundred miles or so from their village, she said, because they had heard of someone else successfully getting treatment from the hospital, and if the same could happen for her grandson, he could join her working as a casual farm labourer. The boy's mother, she said in Hindi, had died when he was very small and, unwanted by other family members because of his sight impairment, had been left in her care. The other woman in the waiting room - whose well-maintained, Bengali silk sari-clad and fair-skinned body stood in sharp 
contrast to that of our interviewee - interrupted her story at this point, turning to me and exclaiming, in English, with her eyebrows raised in alarm: 'Why do they wait until now to come!? When he's grown up already! These people don't take proper responsibility!' She shook her head despairingly and returned to her magazine. Had they come earlier to the hospital, she inferred, the young man might have been cured. Despite the wider circumstances at play - extreme poverty and livelihood pressures, a lack of locally accessible medical care, and family ties stretched by the death of the boy's mother, culpability for his condition was turned back on to his family.

With the 'careless' seen as posing a risk not only to themselves but also to others around them, then, the disabled are constituted as morally questionable. Here, cosmopolitan neo-liberal ideas about individual responsibility and autonomy meet with the remnants of much older, evolutionary notions of the kind once used to justify colonialism, as well as more localized notions about charity. Just as so-constructed 'primitive' peoples were constituted as 'white man's burden' - saved and improved by their colonization - the contemporary failure of socially-excluded groups within India to fulfil their duty of care to themselves and their families justified the intrusion of the State and the medical establishment into the way they managed their day-to-day lives.

\section{Alternative discourses}

Despite an apparent uniformity of opinion across medical and lay discourses, in the same way that colonial authority was never a 'totalized terrain' (Dube 2004:10), neither does the biopower of the Foucauldian imagination entirely encompass how impairments are understood on the ground, its very taken-for-grantedness allowing alternative discourses to flourish unremarked. The generalized 'carelessness' that lay people spoke of was not always considered to be only about ignorance, illiteracy and a 'lack of awareness', even though 
elements of these causes lingered in nearly all my respondents' accounts, and offered the dominant, first-level explanations. When I pressed interviewees to elaborate on why disabled people had been careless, for example, a common theme, across socio-economic, age and gender groups, was that they were negligent about their own care because they had to live in unhygienic conditions: in close-together and cramped slum dwellings without plumbed sanitation, which provided little protection from the elements and allowed the spread of disease to go on unhindered. In this sense, although disability was still blamed on neglect, its victims often lacked the agency to avoid such neglect. Disabled people were also seen as likely to be poor, unable to access or afford adequate treatment. Although, again, dominant 'discourses of truth' depoliticize poverty by relating it to individual or personal development, well over half of my 60 lay informants seemed to recognize, at least implicitly, that more structural factors were also at play. 'The poor have no knowledge of medical care and also have to spend all their time working to make enough just to live, so they naturally neglect their health,' as an engineering student I interviewed at a roadside tea stall put it, succinctly making the point that those on the breadline - like the grandmother and grandson described above - had more pressing concerns than visits to the doctor.

Another family I spent time with over a longer period, in this case in the settlement of physically disabled people on the borders of the city that I visited two or three times a month, were a good illustration of this point. Their daughter, who was affected by polio and could not walk, had been given some initial allopathic treatment. However, her mother said it had been difficult to find the time or resources to give more, particularly when she believed, in accordance with medical opinion, that nothing would restore her daughter's ability to walk. For one thing, their peripheral geographical location, far from transport links, mitigated against visits to hospitals. For another, the mother was reliant on casual, daily waged labour stuffing mattresses to supplement her husband's meagre income from local begging, a poorly 
remunerated task which took up most of the time she was not directly engaged in her now teenaged daughter's care. So, while people did cite 'carelessness' - in the less accusatory sense of an absence of care than a wilful recklessness - to explain why people like this woman's daughter contracted polio in the first place, they also recognized, when pressed, that money and/or access to treatment were also important.

In addition, what also became apparent as I got to know some of my lay informants better, was that their stated views about disability were frequently strongly at odds with their relationships with actual disabled people. Shariff, for example, was an elderly Shia Muslim man who lived close to my apartment. He had handed the running of his shop over to his nephew and now spent much of his day sitting in the street with his friends and watching passers-by. People's lack of care for their own health was a theme he returned to often whenever we discussed disability, the impairments which resulted from such neglect seen as a major hurdle in the development of the country as a whole. People needed to take better responsibility for themselves and for their own actions, he said.

Despite this outwardly rigid, negative stance about disabled people, over the ensuing months Shariff would regularly call me over to introduce disabled friends. Nearly all of them, like him, were urban, middle class Muslims who had run small businesses, and all of them unlike Shariff - sported a range of bodily differences that distinguished them from the mainstream. None of them fitted the stereotypes of disabled people he had described previously, and none of them were presented as being personally culpable. Their impairments, in his view, had been a consequence of kismet - luck; 'Allah's will'; and/or accidents beyond the control of the individual concerned. Likewise, Mohammed, a local shoe-trader in his mid50s, initially blamed the high incidence of disability among the poor on the fact that they sent their children out to work rather than to school. As a result, he told me disapprovingly when I questioned him one day at the roadside, 'they have a lack of awareness and their behaviour is 
often reckless.' Further probing in the weeks that followed, however, revealed that Mohammed's own younger brother had been impaired by a workplace accident - leaving him reliant on a cane to walk - and that one of his closest friends, a guard at a nearby ATM machine, had lost the use of his arm 'through paralysis.' More wistful now than censorious, he told me: 'Like other poor people, they just didn't have the money or the contacts to get the right kind of treatment when they needed it, so what could they do? Even if someone does manage to get together the money, who has the time to go from this clinic to that clinic when you have a family to feed?'

The discrepancy between Shariff and Mohammed's abstract views and those they expressed in relation to particular individuals were particularly marked, but were by no means unique and, among those I got to know quite well, these disjunctures soon became evident in my records of our conversations. In part this was because known disabled people did not represent the 'other' in the ways that abstract conceptions of 'the disabled' did. The discrepancy also arose for at least two further reasons. First, there is a well-documented tendency for respondents to give answers they believe the interviewer wants to hear or which might benefit them [5] (Hammersley and Atkinson 1995:126-133). Second, when people were asked standardized questions, they responded with ready-made answers that required minimal reflection, and which belied the more nuanced perspectives that emerged through conversations over time. In short, the effects of biopower helped to account for first level and official explanations of disability, but masked interpretations shaped by everyday experience.

\section{Challenging assumptions}

While the above has shown that official discourses about disability are not as smoothly internalized by the lay population as my data originally seemed to suggest, my more direct fieldwork with disabled people and their families additionally indicates significant flaws in 
interpreting responses to disability solely as examples of biopower, an explanatory frame that offers very limited perspectives on quotidian realities in Hyderabad.

Firstly, my wider research with disabled recipients of medical attention suggested there was no significant attribution of cause or potential cure to 'the goddess' or to 'superstition', despite nearly all the medical professionals I worked with claiming that their patients from rural areas and urban slums interpreted their conditions in this way. In the case of the families affected by cerebral palsy, more than half of my respondents (59 per cent) from across social and religious divides - identified specific medically-recognized causes. Although causes doctors would classify as non-medical were sometimes mentioned, such as disability as a consequence of misdemeanours in a previous life, these explanations did not exclude medical ones. As elsewhere, people held poly-ontological beliefs (Scott 2007). Lakshmi, for example, was the middle-class mother of Shanti, a nine-year-old girl severely affected by cerebral palsy. On the one hand, she was well-versed in medical explanations of her condition and utilised various prescribed drugs and treatments - on which she could speak authoritatively - to help alleviate her daughter's suffering and improve her day-to-day condition. On the other hand, she was equally certain that conducting special pujas (Hindu religious rituals) and pilgrimages were key to improving Shanti's condition. 'I heard the words of Amma [a spiritual leader] in my ear, calling us to see her in Kolkata, so we went there,' she told me during an in-depth interview at my apartment. 'I've also been advised to do 500,000 of mantras [religious chants]. So far I've managed 90,000 in one sitting. If I manage to achieve at least a 100,000 I think she might also start to walk. I have a lot of faith, a lot of belief in puja. We need to give to God so God will give to us.'

In many cases, explanations also represented conventionalized ways of responding to my questions. 'Sometimes we'll ask, "What sins did we commit for something like to happen?"” as the mother of Gopal, a sight-impaired boy with learning-difficulties, explained it 
to me when I met her in the waiting room of the eye hospital. 'But these are just words, we don't really think in that way. It's just what people say. It just means we don't know how to explain it, so we say that it was God's will.' Such commentary also highlights difficulties in interpreting the results of highly-structured public health research, such as the vignette method adopted by Link and Phelan et al (1999), which offer little potential for probing why informants respond to questions in the ways that they do.

What is also interesting here is that the lower caste, economically poor families I spoke to were less likely than their higher caste counterparts - who, by and large, were formally educated to a higher level and economically wealthier - to attribute their conditions to 'superstition,' despite the prevalent view among health care professionals that it was the poor who were most in need of health education. The explanation given by Gopal's mother who was a daily-waged farm labourer from what the Government classifies as a Scheduled Tribe (ST) - was fairly typical of families in a similar position. They were not necessarily medically well informed, but had faith in medical science to help them, if only they could access it. When karmic causes of disability were discussed and related to action, such as pilgrimages and acts of obeisance to particular Gods, it was usually among my high caste, largely affluent, Hindu informants, for whom religion also played a more central part in their reasoning. These families were also more likely to seek additional treatments to those prescribed, such as Ayurvedic massage for some children with cerebral palsy, which the neurosurgeon I worked with identified as particularly harmful in those cases. Lakshmi, the mother whose poly-ontological beliefs I cited earlier, was an exemplar of this kind of patient: while poorer, less educated patients appeared content to go along with whatever the doctor recommended, their wealthier, more educated counterparts were more likely to take a critical approach to medical recommendations. In Lakshmi's case, this led her to dismiss some of the neurosurgeon's advice, also incorporating Ayurveda, rituals, pilgrimages and physiotherapy 
into her daughter's treatment regime. Even among my wealthier middle-class informants, however, both cause and subsequent treatment tended, at least in interviews with me, to be framed in biomedical terms, and informants nearly always included reference to allopathic doctors alongside other strategies.

Mohammad's story is a good example of this. A 50-year-old unmarried Sunni Muslim man from an economically poor background, Mohammad had lost the use of both his legs, and got around on a Government-scheme sponsored tricycle. I met him at the community of disabled people, where he worked embroidering saris and salwar kameez on a commission basis. When he had developed 'a tumour' on one of his legs as a child, his parents took him 'to so many hospitals and other places.' A fever, combined with cold weather, was suggested as a possible cause, and their response was to seek out whatever help might be available. He told me:

Yes, we visited mosques and shrines. We had tonics and pills prescribed by the doctor and, when they didn't work, we also used Ayurvedic medicine. My grandmother drained the blood from a pigeon, mixed it with biryani oil and applied it to my legs, but it didn't seem to make any difference. There were lots of other treatments too, but here I am. What Allah gave me, He gave. I am God's creation.'

What was striking here and in nearly all the accounts I heard was that people did not, as medical discourse implied, choose local or alternative medicines over biomedicine: rather and particularly in cases where biomedicine did not offer a cure - they tried whatever was at hand. And although the final sentence of Mohammad's quote suggests an acceptance of his bodily status quo, his earlier words belie a straightforward or fatalistic acceptance. For him 
and for nearly all of those I worked with, acceptance, if it came at all, came at the end of a long journey of treatments from a wide range of sources.

While disabled people and their families were, then, generally more receptive to biomedical treatments than popular and official discourses proposed, what my fieldwork also demonstrated was that cause was not, in any case, as straightforwardly biological as a biomedical explanatory model suggests. Several of those I met in the eye hospital particularly those from poorer backgrounds, for whom treatment was potentially free suffered from conditions that had been specifically caused by industrial accidents or were a consequence of poor living conditions. A stone-breaker who had been permanently blinded (and facially disfigured) by an exploding kerosene stove that he was lighting to heat water for tea, for example, might not have been injured had he had access to a gas ring or had the kerosene stove been in a better state of repair. Deprivation - or what Farmer called 'structural violence' (2005) - set the scene for what happened. Disability is not only about individual 'carelessness' or a reluctance to obtain medical treatment; it can also be directly caused by poverty and the particular circumstances within which one is located (Harriss-White 1999:140).

Medical interventions themselves were also identified by a fairly sizeable minority of the families affected by cerebral palsy I interviewed - 16 per cent - as directly causing or worsening the patient's condition. In 13 of these cases, families attributed the condition directly to doctor negligence, such as mistakes made during delivery or a delay in action that could have prevented the condition. In the remaining three cases, interventions to manage other conditions - such as an injection given to bring down a high fever or a blood transfusion - were cited as direct causes of the disability. Although only two of the 82 people I spoke to with sight impairments likewise referred to medical negligence - suggesting that different kinds of impairments are seen as having different causes, and that medical negligence is more 
likely to produce particular conditions - there were also many people, across impairments, who complained that treatment had resulted in few if any benefits or had made the situation worse. Official discourses framed medical intervention as unequivocally positive and all encompassing, bracketing out wider social causes of impairments and potentially negative consequences of treatments. Those working to improve their own or their children's impairments, by contrast, developed subtler interpretations.

Nevertheless, the poor and the uneducated, in contrast to how they were characterized, were usually very willing to seek medical interventions. Perceived medical negligence by one doctor, for example, spurred them on to find other, better ones, not to retreat elsewhere. Lower income groups were, however, confounded in doing so by a number of factors. Firstly, medical costs were prohibitive. A hospital consultation usually cost at least the equivalent of three days' wages for a farm or factory labourer - and, even when treatments were offered by Government hospitals, the costs of x-rays, blood tests and other sundries were significant. Add to this the practical difficulties of accessing care - given that people, like the grandmother-grandson couple described earlier, often lived long distances from services and had other pressures on their time - it is difficult to see how health education, by itself, would lead to a significant upturn in people seeking biomedical treatment.

Even for middle-class informants, who often described themselves as in a worse position than the absolute poor because they had less recourse to government subsidies, balancing cost of treatment against the improvements that such treatment might bring were important considerations. Investing in expensive operations that might allow increased mobility for the patient, for example, were considered, by several families I worked with, only worthwhile if they improved marriage prospects for daughters or employment prospects for sons. If they did not, they argued, limited resources would be better spent on further training for a healthy son or a larger dowry for a healthy daughter. At least the settled siblings might 
then be in a position to care for their disabled siblings after their parents' demise. An operation with minimal practical impact, by contrast, might leave them all in penury. Venkatesh, for example, a small business man whose youngest daughter was severely affected by cerebral palsy, was determined not to spend money on treatment that would be anything less than transformatory. 'Unless it meant that she would be able to marry, go for education and get a job, how can I justify the expenditure?' he said candidly as he walked with me to the bus stop after a lengthy interview with his family. 'I have three other daughters to get married. If all our savings go on my youngest daughter's treatment and she doesn't get better, it's not a good investment.' The value that medical treatment might bring to life, then, cannot be measured simply in terms of the alleviation of physical pain or the extension of physical capacities: value is socially embedded. Public education, then, would only be effective if it went hand-in-hand with more accessible treatment and provided people with a different range of choices.

As Farmer's work on HIV also illustrated, however, 'education' is anyway not a panacea for changing attitudes, and might even make people less likely to receive treatment (2005:xxv), particularly when it is poor quality and, as is often the case, superficial and patronising (Allen \& Parker 2011: 105-107). In relation to leprosy, for example, the biomedical fact that the disease is transmitted via respiration is probably more threatening than certain folk models of disease etiology (White 2002). Leprosy caused by karma, for example, is less feared because it carries no risk of contagion; leprosy caused by an air borne bacteria, in contrast, poses a more significant direct threat (see also Staples 2004:73; 2007b:441; Gussow and Tracy 1970). Similarly, the knowledge that sight impairments were more common among the offspring of consanguineous marriages led to some of my informants fearing that they would be blamed for their children's blindness, making them more likely to hide them away and less likely to obtain timely treatment. 
A further, linked problem concerning public health education about disability is that what biomedicine can offer is often extremely limited. Although the doctors I worked with had improved the lives of many of those they operated upon, cerebral palsy was not a curable disease in the same way, for example, as typhoid. Against what were perceived as such stark realities, education campaigns urging people to seek hospital consultations often raised expectations unrealistically. On several occasions, for example, wealthier families begged me to put them in contact with doctors in the US or in the UK, who, they erroneously assumed, would be able to take them beyond the care available in India.

\section{Conclusion}

I have attempted here to disentangle disability as framed by a hegemonic medical model of disability - within which having a different kind of body to the mainstream is a personal tragedy - from disability as it is experienced by various stakeholders on the ground, intricately caught up in social and political structures and informed by the knowledge that biomedicine is not the only nor always the best framework through which to make sense of and manage bodily differences.

The 'world-making' (Goodman 1978) practices of biomedicine help to shore up and reproduce a relatively stable worldview that continues to dominate the public agenda on disability in India. Responsibility for ill-health, disability and even poverty, is consequently located not within the wider political and economic structures over which biomedicine has no direct influence, but within ill and disabled people and their families. Critiques of biomedical knowledge - and with them wider discussions about structural inequalities, inadequate living conditions, and the absence or lack of access to medical treatment - are successfully bracketed, presenting public health education as a self-evident solution. The lay public is complicit in upholding official 'discourses of truth', not only because of the genuine benefits 
that biomedicine might bring, but because they deflect culpability for disabling conditions away from social institutions, and themselves as individuals, and on to the victim. Responses to disability, from this perspective, require no change to the status quo, just a shift in the behaviour of those careless enough to get themselves into such a position. For the ablebodied, conceptualising the disabled and the sick as a feckless other, captivated by superstition and outmoded practices, allows them to distinguish themselves as modern and stake claims of social superiority (see Pigg 1996; 1997). It is against this background that my interviewees framed their first level discussion of disability in terms of carelessness, a lack of awareness or education, and of superstition and tradition. At the same time, however, despite the lack of a coherent framework through which dissidence from these hegemonic views might be expressed, on closer inspection alternative perspectives on the causes of disability did emerge, suggesting that, in a context where most people had limited access to technologies of self-care, there were significant discrepancies between public rhetoric and a more nuanced understanding of the structural constraints that particular disabled people and their families lived under. It was not, however, simply that the lay public were more sympathetic to the constraints facing disabled people than their rhetoric implied: the poor, contra stereotype, were also less resistant to biomedical solutions than their affluent peers, and were usually keen to access medical support when socio-economic circumstances permitted. Against such a background, calls for more public health education will continue to fail to miss their intended targets.

\section{Notes}

1 Castes are generally defined as Hindu, birth-ascribed, endogamous social categories, organised into contested hierarchies, ranging from what, from a top-down perspective, are 
identified as the ritually impure ex-untouchable castes to the warrior Kshatriya and priestly Brahmin castes.

2 State reclassifications of caste groups previously labelled as 'untouchables' as Scheduled Caste (SC) and Scheduled Tribes (ST) had been expanded to include Other Backward Castes (OBC) - those considered economically and socially backward, despite ranking higher in a model of caste predicated in relative purity or impurity (cf. Dumont 1970) - and Other Castes

(OC) for those remaining. Such classifications allow Government reservations of public sector jobs to be allocated to those considered most excluded.

\section{References}

Allen, Tim and Parker, Melissa

2011 The 'Other Diseases' of the Millennium Development Goals: rhetoric and reality of free drug distribution to cure the poor's parasites, Third World Quarterly 32: 1, 91117.

Barnes, C. \& G. Mercer

2003 Disability. Cambridge: Polity.

Braun, B.

2007 Biopolitics and the molecularization of life. Cultural Geographies 14:6-28.

Cheah. P.

2007 Biopower and the new international division of reproductive labor. Boundary 2:79-113.

Dube, $S$.

2004 Stitches on time: colonial textures and postcolonial tangles. Durham, N.C.: Duke University Press.

Dumont, L. 
1970 Homo hierarchicus: the caste system and its implications. London: Weidenfeld and Nicholson.

Ecks, S.

2004 Bodily sovereignty as political sovereignty: self care in Kolkata, India. Anthropology and Medicine 11, 75-89.

Farmer, P.

2005 Pathologies of power: health, human rights, and the new war on the poor.

Berkeley: University of California Press.

Foucault, M.

1978 The history of sexuality, volume one. New York: Random House.

1994 Two lectures. In Critique and power: recasting the Foucault/Habermas debate

(ed.) M. Kelly, 17-46. Cambridge, Mass.: MIT Press.

Geffen, N.

2005 Echoes of Lysenko: state-sponsored pseudo-science in South Africa. Social Dynamics 31, 183-210.

Goodman, N.

1978 Ways of worldmaking. Indianapolis: Hackett.

Gussow, Z. \& T. Tracy

1970 Stigma and the leprosy phenomenon: the social history of a disease in the nineteenth and twentieth centuries. Bulletin of the History of Medicine 44, 425-49.

Hammersley, M. \& P. Atkinson

1995 Ethnography: principles in practice, second edition. London: Routledge.

Hannah, Matthew. G.

2011 Biopower, life and left politics. Antipode, 43:1034-1055.

Harriss-White, B. 
1999 On to a loser: disability in India. In Illfare in India: essays on India's social sector in honour of S. Guhan B. Harriss-White \& S. Subramanian, eds., pp135- 38. New Delhi: Sage.

Leach, M. \& J. Fairhead

2007 Vaccine anxieties: global science, child health \& society. London: Earthscan.

Link, Bruce G., Jo C. Phelan, Michaeline Bresnahan, Ann Stueve, Bernice A. Pescosolido. 1999 Public perceptions of mental illness: labels, causes, dangerousness and social distance. American Journal of Public Health, 89, 9:1328-1333.

Niehaus, I.

2009. Using antiretrovirals in Bushbuckridge, South Africa: notes of treatment literacy and therapeutic efficacy. Unpublished conference paper. Leipzig: African European Group for Interdisciplinary Studies.

Oliver, $\mathrm{M}$.

1990. The politics of disablement. London: Macmillan.

Pigg, S. L.

1997 'Found in most traditional societies': traditional medical practitioners between culture and development. In International development and the social sciences: essays on the history and politics of knowledge (eds) F. Cooper \& R. Packard, 259-90. Berkeley: University of California Press.

1996 The credible and the credulous: the question of 'villagers' beliefs' in Nepal. Cultural Anthropology 11, 160-201.

Rabinow, P. \& N. Rose (eds)

1994 The essential Foucault: selections from the essential works of Foucault 19541984. London: The New Press.

Rose, N. 
2006 Politics of life itself: biomedicine, power and subjectivity in the twenty-first century. Princeton: Princeton University Press.

1990. Governing the soul; the shaping of the private self. New York: Routledge.

Saethre, Eirik and Jonathan Stadler

2009 A tale of two 'cultures': HIV risk narrative in South Africa. Medical Anthropology 28, 3: 268-284.

Scott, M.

2007 The severed snake: matrilineages, making place, and a Melanesian Christianity in Southeast Solomon Islands. Durham, N.C.: Carolina Academic Press.

Shakespeare, $\mathrm{T}$.

2006 Disability rights and wrongs. London: Routledge.

Shuttleworth, R. \& D. Kasnitz

2004 Stigma, community, ethnography: Joan Ablon's contribution to the anthropology of impairment-disability. Medical Anthropology Quarterly 18, 139-61.

Staples, James

2004 Delineating disease: self-management of leprosy identities in South India.

Medical Anthropology 23, 69-88.

2007a Peculiar people, amazing lives: leprosy, social exclusion and community

making in South India. Delhi: Orient Longman.

$2007 b$ The "leper" and the state in South India. Economic and Political Weekly 42, 437-43.

2011 At the intersection of disability and masculinity: exploring gender and bodily difference in India. Journal of the Royal Anthropological Institute, 17, 3: 545-562.

Star, Shirley

1955 The public's ideas about mental illness. Paper presented at Annual Meeting of the 
National Association for Mental Health, Indianapolis.

Thomas, C. \& M. Corker

2002 A journey around the social model. In Disability/postmodernity: embodying disability theory (eds) M. Corker \& T. Shakespeare, 18-31. London: Continuum. Tremain, S.

2002 On the subject of impairment. In Disability/postmodernity: embodying disability theory (eds) M. Corker \& T. Shakespeare, 32-45. London: Continuum.

Volpp, Leti

2000 Blaming culture for bad behaviour. Yale Journal of Law and the Humanities. 12: 89-117.

White, C.

2002 Sociocultural considerations in the treatment of leprosy in Rio de Janeiro, Brazil. Leprosy Review 73, 356-65. 